\title{
Giant Condyloma (Buschke-Loewenstein Tumor) in a 16-year-old Patient: Case Report
}

\section{Condiloma gigante (tumor de Buschke-Loewenstein) em uma paciente de 16 anos: relato de caso}

\author{
Caetano Galvão Petrini ${ }^{1}$ Patrícia Pereira dos Santos Melli ${ }^{2}$ Pedro Sérgio Magnani \\ Laura Penna Rocha ${ }^{3}$ Francesca Maia Faria ${ }^{4}$ Geraldo Duarte ${ }^{2}$ Silvana Maria Quintana ${ }^{2}$
}

\footnotetext{
${ }^{1}$ Hospital das Clínicas de Ribeirão Preto, Universidade de São Paulo (USP), Ribeirão Preto, SP, Brazil

2 Gynecology and Obstetrics Department, Ribeirão Preto Faculty of Medicine, USP, Ribeirão Preto, SP, Brazil

${ }^{3}$ General Pathology Division, Biological and Natural Sciences

Institute, Universidade Federal do Triângulo Mineiro, Uberaba, MG, Brazil

${ }^{4}$ Pathology and Forensic Medicine Department, Ribeirão Preto

Faculty of Medicine, USP, Ribeirão Preto, SP, Brazil
}

\begin{abstract}
Address for correspondence Caetano Galvão Petrini, MD, Departamento de Ginecologia e Obstetrícia, Faculdade de Medicina de Ribeirão Preto, Universidade de São Paulo, Av. Bandeirantes, $n^{\circ}$ 3900, $8^{\circ}$ andar. Monte Alegre, 14049-900. Ribeirão Preto, SP, Brazil (e-mail: caepetrini@yahoo.com.br).
\end{abstract}

Rev Bras Ginecol Obstet 2016;38:471-476.
Abstract
Keywords
- giant condyloma
- Buschke-Loewenstein tumor
- human papillomavirus
- HPV
- surgical treatment

\section{Resumo \\ Palavras chave \\ - condiloma gigante \\ - tumor de Buschke- Loewenstein \\ - vírus do papiloma humano \\ - HPV \\ - tratamento cirúrgico}

The Buschke-Loewenstein tumor is characterized by excessive growth of verrucous lesions on the genitals and/or perianal region. It is considered benign despite the high rate of recurrence and the possibility of malignant transformation. It is commonly associated with subtypes 6 and 11 of the human papillomavirus (HPV), and host's immunity plays an important role in the development of the disease. Surgical excision is the recommended treatment in most cases. We present the case of a 16 years old female patient with extensive vulvar lesions successfully treated surgically.

O tumor de Buschke-Loewenstein se caracteriza pelo crescimento excessivo de lesões verrucosas na região genital e/ou perianal. É considerado benigno apesar da elevada taxa de recorrência e da possibilidade de transformação maligna. Está comumente associado aos sorotipos 6 e 11 do papiloma vírus humano (HPV) e a imunidade do hospedeiro tem importante papel no desenvolvimento da doença. A excisão cirúrgica é o tratamento recomendado na maioria dos casos. Apresentamos o caso de uma paciente do sexo feminino, de 16 anos, com lesão vulvar de grande extensão tratada cirurgicamente com sucesso. received

March 16, 2016

accepted

September 12, 2016
DOI http://dx.doi.org/ 10.1055/s-0036-1593776. ISSN 0100-7203.
Copyright $@ 2016$ by Thieme Publicações License terms

Ltda, Rio de Janeiro, Brazil
(요 (1) $\odot$ 


\section{Introduction}

In 1925, Abraham Buschke and Loewenstein Ludwig described a penis tumor that had intermediate characteristics between acuminated condyloma and squamous cell carcinoma. ${ }^{1}$ These authors denominated this tumor Buschke-Loewenstein Tumor (BLT) or giant condyloma. The BLT is included in the verrucous carcinoma category, which also comprises oral florid papillomatosis, Ackerman tumor and cuniculatum epithelioma. However, although they provide considerable local destruction, these lesions do not produce distant metastases. ${ }^{2,3}$

The etiology of this tumor is an infection by Human Papillomavirus (HPV), usually the subtypes 6 and $11^{4,5}$ Among the risk factors for the development of these lesions, we highlight smoking, having multiple sex partners, chronic genital infections, poor hygiene and immunodeficiencies. ${ }^{3}$ Moreover, rearrangements in the upstream regulatory region (URR) of the HPV 6 DNA may occur naturally, leading to an additional risk factor to the host, as this HPV genome change predominates in histologically or clinically more aggressive lesions, as observed in some cases of BLT. ${ }^{6}$

In a review of 51 cases published in the literature, a higher frequency of the disease was observed in men (male/female rate $2.7: 1$ ), and in ages below 50 years old, a rate of 3.5:1. The average age of occurrence in women was 46.6 years old; however, with a tendency of occurrence at earlier ages. ${ }^{7}$ Moreover, the incidence of anogenital warts is increasing in children, which may be a reflection of the high incidence of this infection in adults. However, giant condyloma acuminatum is an extremely rare clinical type of genital wart in the pediatric population. $^{8}$

\section{Case Presentation}

KAAM, 16 years old, without previous diseases, reporting illicit drug use (marijuana and cocaine), alcoholism and homosexual and heterosexual relationships. Patient claimed beginning sexual activity at 14 years old. Serologic screening for HIV, Hepatitis B (HBsAg), hepatitis C (anti-HCV ELISA) and syphilis (VDRL) did not reveal infections and patient had not mentioned any previous sexual diseases.

September 2013: appearance of verrucous lesions on the vulva. The medical evaluation diagnosed pelvic inflammatory disease (PID) and condylomatous vulvar. It was prescribed ambulatory treatment for PID and podophyllotoxin $0.5 \%$ for condyloma. The patient underwent the treatment for PID, but did not use the local treatment for condyloma correctly and, consequently, the lesions increased.

October 2013 (-Fig. 1A): A new assessment was performed and a significant growth of the vulvar lesions was observed. Imiquimod 5\% ointment was prescribed, to be applied 3 times per week. However, there was no visible improvement.

November 2013: regression of the condyloma was not observed and the patient had secondary infection of the lesion. She was hospitalized and treated with intravenous antibiotics (-Fig. 1).

January 2014: patient is referred to the Department of Infectious Diseases in Obstetrics and Gynecology of the Ribeirão Preto Medical School, at Universidade de São Paulo, reporting appearance, since September of 2013, of condyloma lesions in the vulva that did not respond to prescribed treatments (4 months of evolution). The patient remained hospitalized for 30 days because lesions showed accelerated growth, making walking, urinating and defecating difficult, and also presenting secondary infection.

Gynecological examination in January of 2014: vegetating lesion, exophytic, occupying the entire length of the labia majora and perianal region, with areas of necrosis, erosion and fetid smell, measuring $\sim 15 \mathrm{~cm}$ in length bilaterally and $\sim 7 \mathrm{~cm}$ thick; it is not possible to perform speculum examination or vaginal examination because of the extent of the injury ( - Fig. 1 ).

On January 24 of 2014, wide local excision was performed with radiofrequency waves surgery, leaving the wound open to heal by secondary intention. Patient remained hospitalized, with daily dressing changes, for 4 days, and was discharged with surgical wound in healing process. The granulation tissue aspect showed no signs of local infection (-Fig. 2).
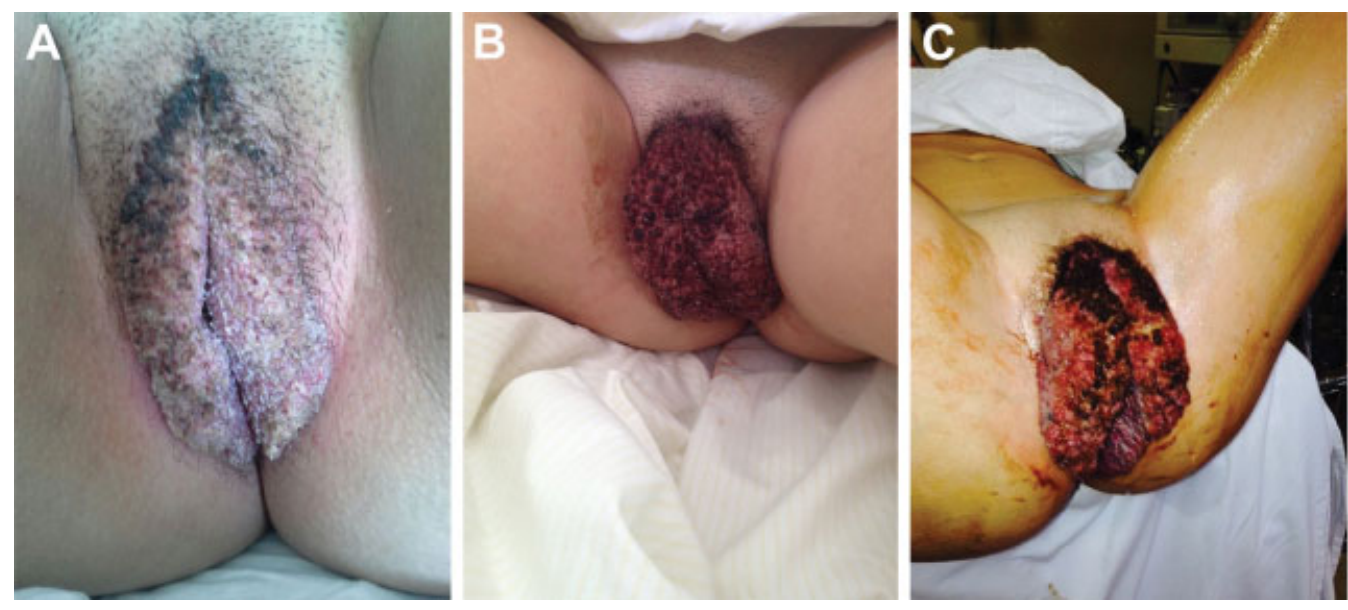

Fig. 1 Evolution of injury: (A) October, 2013; (B) November, 2013; (C) January, 2014. 

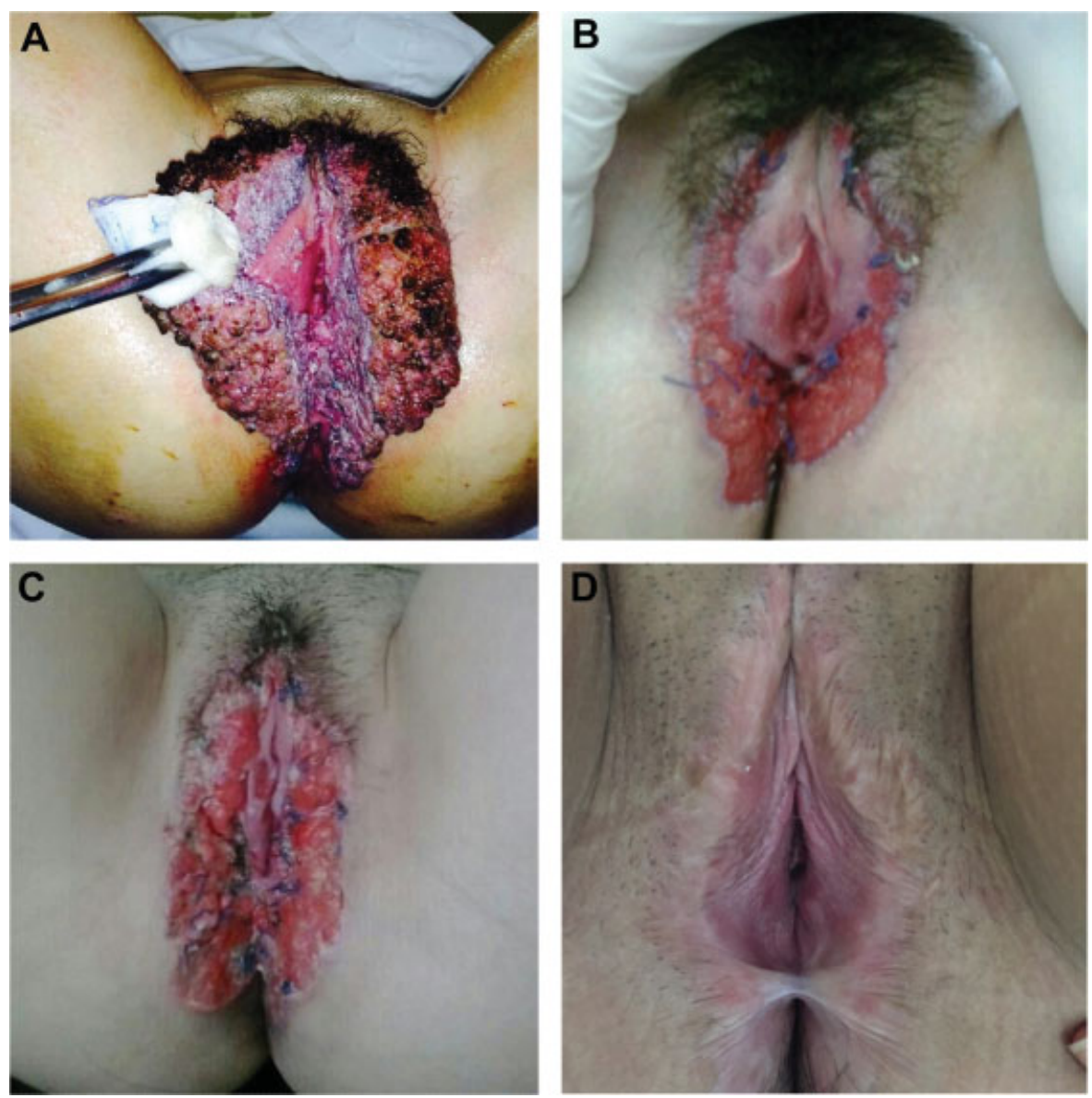

Fig. 2 Before and after surgery: (A) preoperative; (B) immediate postoperative period; (C) fourth day postoperative; (D) 12 months postoperative.

Result of the histopathological study of the lesion: giant condyloma, and no detectable malignant transformation in the samples. Chromogenic in situ hybridization (CISH) was positive for low-risk HPV (-Fig. 3 ).

First review performed 60 days after surgery (February 25 , 2014): patient without complaints.

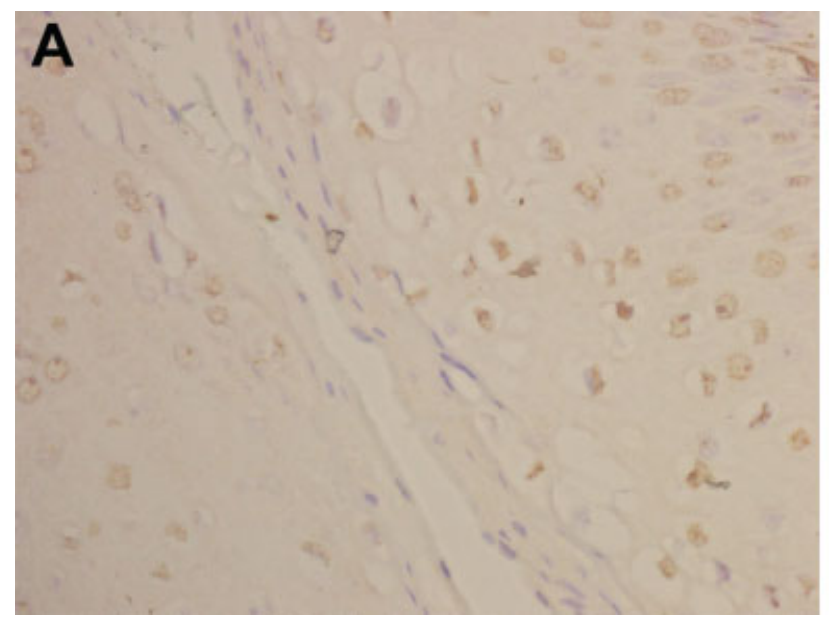

Colposcopy: satisfactory results. Squamocolumnar junction (SCJ) in 0, type 2 transformation zone, with minor findings of abnormal colposcopy.

Vagina: low-grade lesion in the anterior vaginal background. Vulva without lesions (-Fig. 2D).

Colpocytology: satisfactory with atypical squamous cells of undetermined significance suggesting repair (ASCUS)

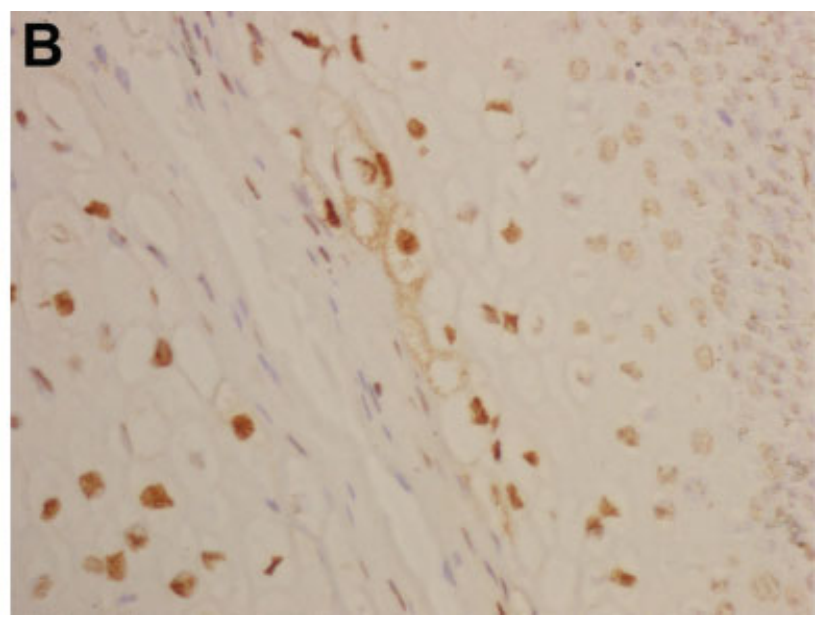

Fig. 3 Chromogenic in situ hybridization (CISH); A: high risk HPV (negative CISH, 400X); B: low risk HPV (positive CISH, 400X). 

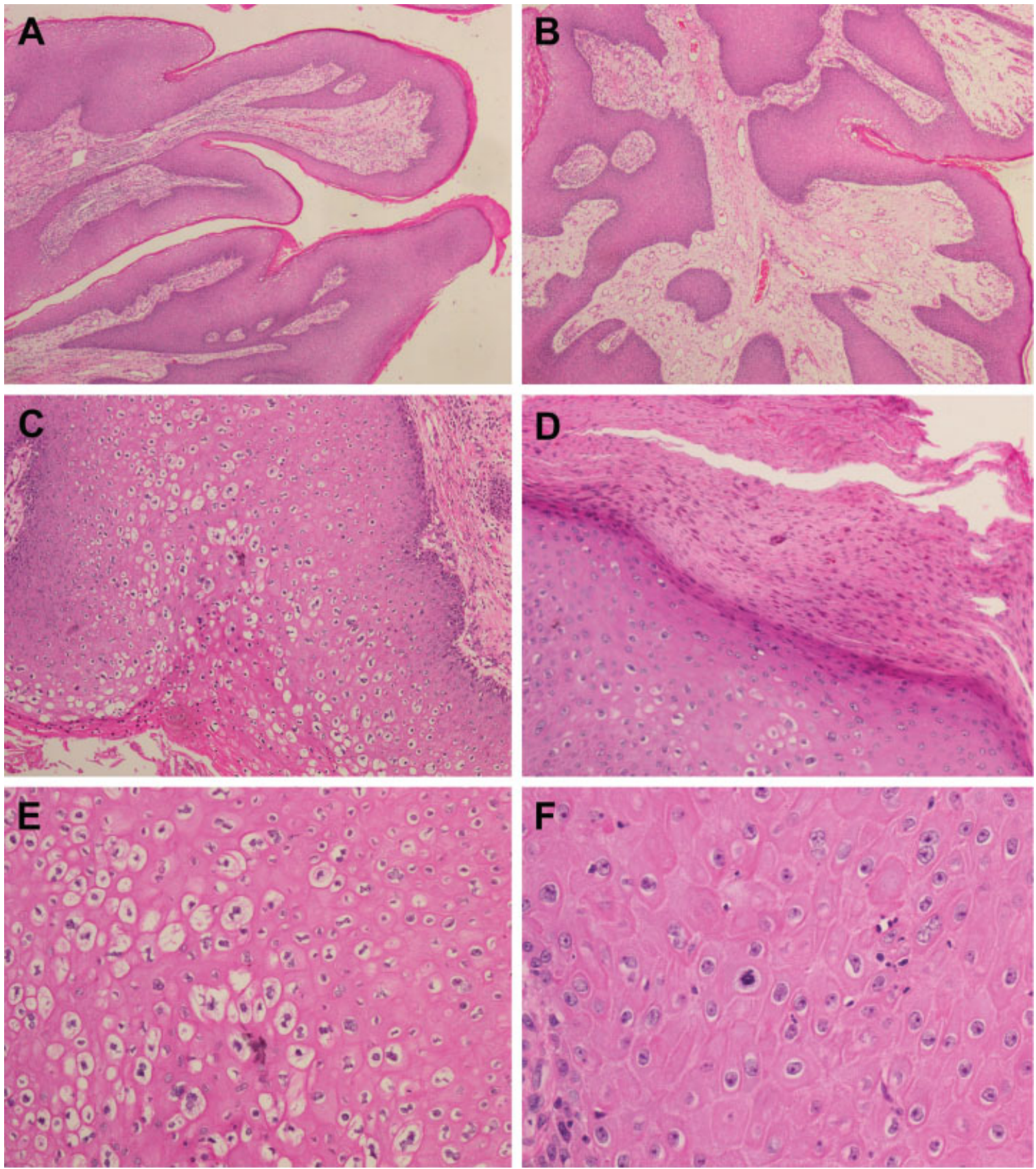

Fig. 4 Lesion Microscopy: (A) Architecture of papillary area (HE, 40x); (B) Area of endophytic projections, with rare rounded blocks infiltrating the stroma (HE, 40x); (C) Area of frequent koilocytosis (perinuclear halos, binucleation and nuclear atypia) and parakeratosis (HE, 100x); (D) Hyperkeratosis and parakeratosis area (HE, 200x); (E) Koilocytosis area (HE, 200x); (F) Evidence of increased atypical mitotic activity (HE, 400x).

Polymerase Chain Reaction (PCR) for the main HPV types 6, 11, 16, 18 (HPV PCR): Positive.

Cervical and vaginal biopsy confirming cervical intraepithelial neoplasia grade I (CIN I) and vaginal intraepithelial neoplasia grade I (VIN I) respectively, and opted for expectant management.

Second review (06/01/2015): A year after excision of giant condyloma and 12 months of expectant management for CIN I and VIN I.

Cervix: Normal colposcopy, with squamocolumnar junction in zero, type 2 normal transformation zone.

Vagina: without lesions.
Vulva: without verrucous lesions, with retraction and discrete hypochromic at the site of excision of the lesion (-Fig. 2D).

Colpocytology in this date was satisfactory without atypia and the HPV PCR test was negative.

\section{Discussion}

The Buschke-Loewenstein tumor is characterized by the slow growth of exophytic verrucous lesions that infiltrate the surrounding tissues. Among its complications, we highlight secondary infection, fistulas and necrosis. The most frequent site of appearance is the genital region, mainly 
affecting the vulva in women and balanopreputial area in men, but may affect the scrotum, rectum and bladder. This tumor is always preceded by acuminated condyloma, and host's immunodeficiency has an important role for the development of the disease. Possible differential diagnosis is verrucous squamous cell carcinoma. ${ }^{9}$ Patients with lesions with increased susceptibility to rapid progression and higher recurrence rates generally have various types of immunodeficiency, which may lead to difficulty in the assessment of best treatment option. ${ }^{10}$

The biological behavior of BLT is intermediate between acuminated condyloma and squamous cell carcinoma and may undergo malignant transformation in $30-56 \%$ of cases, and rarely leads to metastasis. ${ }^{11}$ Histological evaluation allows the performance of differential diagnosis because the giant condyloma has high mitotic activity, acanthosis, important papillomatosis, thick edges and tumor infiltration of adjacent tissues not infiltrating the basement membrane. $^{12}$

In the presented case, the history of large tumor occupying the entire perineal area, together with the findings and histopathological examination of marked papillomatosis, acanthosis, hyperkeratosis, parakeratosis, koilocytosis and increased presence of atypical mitosis confirm the suspected diagnosis of BLT (-Figs. 1 and $\mathbf{4}$ ).

The treatment of choice for BLT remains controversial, but surgery seems to be the best option. A wide surgical excision, healing by secondary intention, or radical local excision with reconstruction of skin defects have been the main treatments described. ${ }^{13}$ Other treatments with $\mathrm{CO} 2$ laser, radiation therapy, intralesional injection of interferon alfa or topical imiquimod can be used as an alternative treatment, especially in cases where surgical resection can be mutilating in cases of locally advanced disease, which prevents the resection with safety margins in patients without clinical conditions to perform surgery. ${ }^{14}$

A long postoperative follow-up is necessary because the disease has a high rate of recurrence, and early treatment of recurrent lesions must be performed. ${ }^{15}$ Moreover, biopsy should be performed in all cases because of the risk of malignant transformation. ${ }^{16}$ There are some reports of successful long-term imiquimod treatments, avoiding major surgery or allowing realization of minor surgery for residual lesions. ${ }^{17}$ However, in the case presented, the injury led to losses in essential functions such as urination and evacuation, as well as secondary infection, not allowing wait.

We present a case of a 16-year-old patient with alcohol consumption and use of illicit drugs, which are factors associated with immunosuppression. ${ }^{18,19}$ This case gets attention for fact that the disease in this patient, has appeared $\sim 30$ years earlier than the average age found in the literature. This finding is in accordance with Trombetta and Place ${ }^{7}$, who also observed a recent trend toward a younger presentation of the BLT. ${ }^{7}$

In this case the lesion had a rapid growth (4 months of evolution), which was successfully treated surgically, without occurrence of postoperative complications. Despite the high risk of recurrence of the disease $(60-70 \%),{ }^{20}$ this case presents no evidence of new lesions following 12 months post-resection. The fact that the patient had ceased alcohol consumption and the use of illicit drugs may have contributed to the success of the treatment and the absence of recurrence.

\section{Conclusion}

The Buschke-Loewenstein tumor is a sexually transmitted disease caused by low-risk HPV, with benign histological features, but with an excessive local growth and high recurrence rates. The overgrowth makes the hygiene difficult and increases the risk of secondary infections. In addition, the social and psychological damage brought up by the stigmas of the disease are difficult to measure. Therefore, a follow up with a multidisciplinary team is very important. Especially in cases such as the one presented, in which the patient was a teenager and had multiple risk factors for developing the disease, such as drug addiction and risky sexual behavior, a multidisciplinary approach is necessary for a successful treatment.

\section{References}

1 Steffen C. The men behind the eponym-Abraham Buschke and Ludwig Lowenstein: giant condyloma (Buschke-Loewenstein). Am J Dermatopathol 2006;28(6):526-536

2 Schwartz RA. Verrucous carcinoma of the skin and mucosa. J Am Acad Dermatol 1995;32(1):1-21, quiz 22-24

3 Spinu D, Rădulescu A, Bratu O, Checheriță IA, Ranetti AE, Mischianu D. - Giant condyloma acuminatum - Buschke-Lowenstein disease a literature review. Chirurgia (Bucur) 2014;109(4):445-450

4 Gissmann L, deVilliers EM, zur Hausen H. Analysis of human genital warts (condylomata acuminata) and other genital tumors for human papillomavirus type 6 DNA. Int J Cancer 1982;29(2): 143-146

5 Dianzani C, Bucci M, Pierangeli A, Calvieri S, Degener AM. Association of human papillomavirus type 11 with carcinoma of the penis. Urology 1998;51(6):1046-1048

6 Rübben A, Beaudenon S, Favre M, Schmitz W, Spelten B, Grussendorf-Conen EI. Rearrangements of the upstream regulatory region of human papillomavirus type 6 can be found in both Buschke-Löwenstein tumours and in condylomata acuminata. J Gen Virol 1992;73(Pt 12):3147-3153

7 Trombetta LJ, Place RJ. Giant condyloma acuminatum of the anorectum: trends in epidemiology and management: report of a case and review of the literature. Dis Colon Rectum 2001;44(12):1878-1886

8 Suárez-Ibarrola R, Heinze A, Sánchez-Sagástegui F, et al. Giant condyloma acuminatum in the genital, perineal and perianal region in a pediatric patient. Literature review and case report. Urol Case Rep 2016;7:14-16

9 Hicheri J, Jaber K, Dhaoui MR, Youssef S, Bouziani A, Doss N. Giant condyloma (Buschke-Löwenstein tumor). A case report. Acta Dermatovenerol Alp Panonica Adriat 2006;15(4):181-183

10 Niazy F, Rostami K, Motabar AR. Giant condyloma acuminatum of vulva frustrating treatment challenge. World J Plast Surg 2015; 4(2):159-162

11 Bertram P, Treutner KH, Rübben A, Hauptmann S, Schumpelick V. Invasive squamous-cell carcinoma in giant anorectal condyloma (Buschke-Löwenstein tumor). Langenbecks Arch Chir 1995; 380(2):115-118

12 Knoblich R, Failing JF Jr. Giant condyloma acuminatum (BuschkeLöwenstein tumor) of the rectum. Am J Clin Pathol 1967;48(4): 389-395 
13 Gole GN, Shekhar T, Gole SG, Prabhala S. Successful treatment of buschke-löwenstein tumour by surgical excision alone. J Cutan Aesthet Surg 2010;3(3):174-176

14 Martin JM, Molina I, Monteagudo C, Marti N, Lopez V, Jorda E. Buschke-Lowenstein tumor. J Dermatol Case Rep 2008;2(4):60-62

15 Dinleyici M, Saracoglu N, Eren M, et al. Giant condyloma acuminate due to human papillomavirus type 16 in an infant successfully treated with topical imiquimod therapy. Dermatol Rep 2015 ; $7(3): 6134$

16 Ganem NS, Silva BC, Nascimento MLFO, et al. [Giant condyloma acuminatum: a case report]. J Bras Doenças Sex Transm 2010; 22(4):222-224
17 Coelho FMP, Mano AL, Bacellar MS, Codes LMG, Souza ELQ, Azaro Filho EM. [Buschke-Lowenstein tumor: imiquimod therapy to esphincter preservation. Case report]. Rev Bras Colo-Proctol. 2008;28(3):342-346 Portuguese.

18 Szabo G. Consequences of alcohol consumption on host defence. Alcohol Alcohol 1999;34(6):830-841

19 Zhao H, Ye TH. [Drug abuse and infection]. Zhongguo Yi Xue Ke Xue Yuan Xue Bao 2006;28(6):858-861 Chinese.

20 Chu QD, Vezeridis MP, Libbey NP, Wanebo HJ. Giant condyloma acuminatum (Buschke-Lowenstein tumor) of the anorectal and perianal regions. Analysis of 42 cases. Dis Colon Rectum 1994; 37(9):950-957 